\title{
Single Phase AC Current Controller by Using Hysteresis Method
}

\author{
Zulkhairi ${ }^{1,{ }^{*}}$, Mochammad Facta $^{2 *}$, Trias Andromeda ${ }^{2}$, Hermawan $^{2}$ and Iwan Setiawan ${ }^{2}$ \\ ${ }^{1}$ Magister Study Program of Electrical Engineering, Diponegoro University, Semarang - Indonesia \\ ${ }^{2}$ Department of Electrical Engineering, Faculty of Engineering, Diponegoro University, Semarang - Indonesia
}

\begin{abstract}
Generally, the electrical power supply acts as a voltage source only but many applications, current sources are needed. In conventional methods, to provide a current source, an electric power supply with variable voltage is adjusted to give the amount of current. In some electrical applications and devices, there is a demand to have a constant voltage with a variable current. This paper proposes a single phase alternating current controller as a power supply with a current source that can be adjusted using the hysteresis method. The advantage of the hysteresis method is that the electric current can follow changes in setting values and have a good response to any changes in the load given. This method, the actual current can follow the reference flow as needed. During testing, the inverter has succeeded in producing 3 Ampere $50 \mathrm{~Hz}$ at the output voltage of 50 Volt which is sent to the load. In applications, the proposed power supply is useful as an inverter to convert DC current into AC current. Furthermore, this proposed inverter has the opportunity as a renewable energy resource converter to convert direct current from photovoltaic to alternating current for various electronic devices in industries and households.
\end{abstract}

Keywords: Hysteresis; inverter; single phase.

\section{Introduction}

Electronic power components are needed to increase productivity in the industry. Electronic components require a high quality power supply so that these components need to be supplied by a constant frequency and magnitude to reduce electromagnetic errors [1]. The high dependency on electricity has resulted in an energy crisis. In addition, to provide electrical power, alternative energy sources have become important to be applied [2].

Conventionally, in a renewable energy resource converter, voltage source inverter is applied. Inverters are usually used in uninterrupted power supply systems and off-grid renewable energy systems. A Distorted current creates problems with connected loads, such as loss and vibration in motor, so an inverter control system is needed to maintain the output voltage with a small error rate [3].

In many other applications, it is important to have a current source instead of the voltage source above. The current source is possible to be designed by applying the current controller method. The objective of this paper is to present the design of the current control system using the hysteresis method by controlling the upper and lower limits of a single phase inverter so that it can be synchronized with the reference current. The hysteresis method is widely used because the application is simple and the current loop control response is desirable, also a parameter changing does not affect the response [4].

\section{System Model}

\subsection{Inverter}

The inverter is a device for converting direct current (DC) power into alternating current (AC) power. The input of the inverter can be supplied from a battery, fuel cell, or power supply [5]. In the past, the use of inverters was only used in some main application which would be large-scale applications. Now, inverter is an electronic device which used on many electrical types of equipment or devices. The additional advantage of an inverter is not just because the inverter can convert DC power into AC but inverter has high efficiency, can reduce power costs, and versatile application [6]. Inverters are classified as Series Inverter, Parallel Inverter, and Bridge Inverter. Bridge Inverter is classified into two types, these types are Half Bridge and Full Bridge Inverters [5]. Full bridge type inverter has maximum output voltage the same as the input voltage. A full bridge inverter has a large power with small current stress compared to other inverter topologies [7]. The choice of the right type of inverter has a great influence on its optimum performance [8]. Inside the inverter, it is possible to have the rectifier circuit [9]. On the power supply uses a rectifier; the AC signal will be converted to $\mathrm{DC}$ bypassing the rectifier's output through a filter. This is intended to eliminate ripples from AC components. The rectifier circuits can be built using diodes. Rectifier circuit has three basic types namely half-wave rectifier, full-wave rectifier, bridge rectifier [10].

\footnotetext{
* Corresponding author: zulkhairi.jr@gmail.com; facta@elektro.undip.ac.id
} 


\subsection{Hysteresis Control}

Hysteresis is a controlled technique that is often used because it has simplicity of implementation, stable and does not require any carrier. The reference current and the load current that are compared should not have errors that exceed the upper and lower limits [11].

The hysteresis control compares the actual signal and the reference signal. From the comparison, there are error signals which will be fed back to the switching pattern. The hysteresis control has an upper and lower limit where if the error signal is between these limits then there is no switching [1].

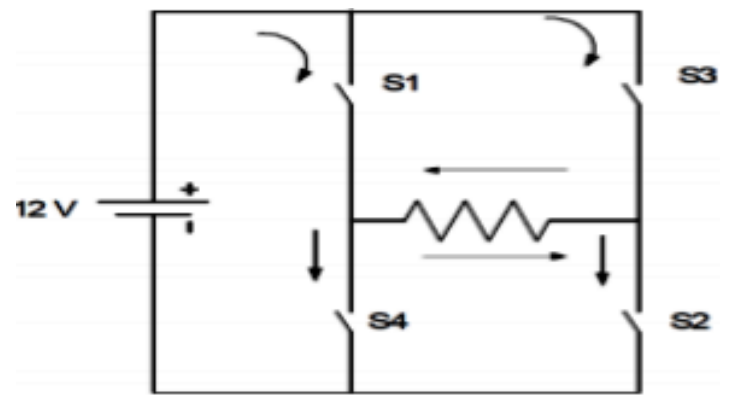

Fig. 1. Working principle of an inverter.

Fig. 1 shows the working principle of an inverter is if the switch $S_{1}$ and $S_{3}+V_{D C}$ are on position then the load current will be electrified from right to left and the current will rise. If the switch $\mathrm{S}_{2}$ and $\mathrm{S}_{4}$ are in position then the load current will be electrified from left to right and the current falls. This condition is the principle of alternating current (AC) in one period of a sinusoidal wave with the first half wave positive and the second half wave negative [12].

The magnitude of direct current voltage (VDC) and the load inductance affect the rate of current rise and fall during one wave. If the current has a faster rise and fall then the time needed by the current will go out of the hysteresis boundaries become smaller. Then, if the error tolerance inside hysteresis bandwidth is reduced it will increase the switching frequencies. But, if switching frequencies are operated too high, they may get damaged due to overheating. So, during the design of the hysteresis controller, it is important to consider a realistic and feasible switching frequency, current error rate, load inductance, and the dc voltage $\mathrm{V}_{\mathrm{DC}}[11]$.

\section{Design}

\subsection{Hysteresis Current Control}

Hysteresis is used to control the actual ( $i_{\text {actual }}$ ) current coming out of the inverter with the limits specified in the program where the limit serves to adjust the sinusoidal variable of the reference current provided by the controller. Error value $(e)$ is the result of a comparison between the output value of the current sensor from the inverter $\left(i_{\text {actual }}\right)$ and the reference current value $\left(i_{\text {ref }}\right)$ where the reference value is set using a potentiometer.
The error value obtained is controlled by the microcontroller using the hysteresis method to produce signal control based on the value of the error obtained. Block hysteresis current control diagram can be seen in Fig 2.

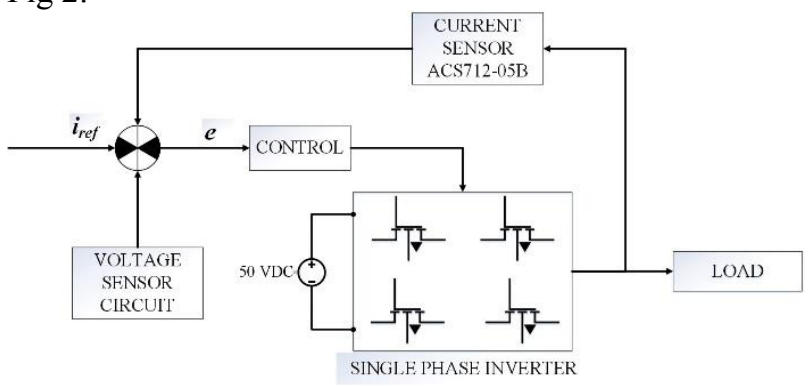

Fig 2. Block diagram of hysteresis controller.

\subsection{Hardware Plant}

The main block of this inverter shown in Fig. 3 are a single-phase AC voltage source, a control module with the dsPIC30F4011 microcontroller, full-wave bridge rectifier, TLP MOSFET driver, ACS712-05B current sensor, Digital to Analog Converter (DAC) AD7302, voltage sensor, and load.

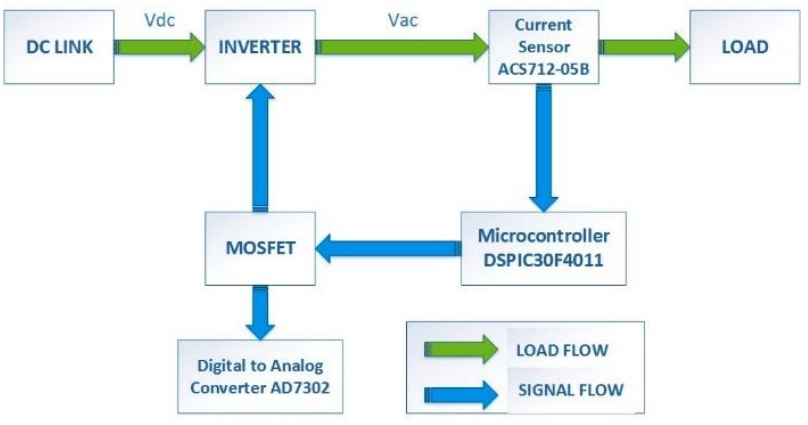

Fig. 3. Block Diagram Inverter Single Phase Hysteresis

Single phase AC voltage source has a function as a power supply for the main circuit and control circuit. The 16-Bit DSPIC30F4011 microcontroller is used to produce a hysteresis signal for the actual current measured on the sensor and the reference current. DC supply voltage in the inverter is obtained from AC voltage by using a rectifier bridge.

A full bridge single-phase inverter has 4 switches from MOSFET IRF460. The applied driver is TLP250. The supply voltage on the MOSFET is $15 \mathrm{~V}$ DC and the power supply for the DSPIC30F4011 microcontroller is obtained from the transformer output and a full wave rectifier.

The inverter output is measured using an ACS712 current sensor which is sent to DSPIC30F4011 via Analog to Digital Converter (ADC). The outgoing voltage functions as a representation of the actual current and the reference current is displayed via Digital to Analog Converter (DAC) AD7302 to the display of oscilloscope. The voltage sensor circuit is used so that the signal from the voltage can be read by the DSPIC30F4011 microcontroller. 


\section{Simulation and Experiment Result}

\subsection{Simulation}

Before executing the hardware, the simulation of singlephase inverter in Matlab is made and tested to know the difference in value from control hysteresis. Fig. 3 shows a single phase inverter block diagram. Controller hysteresis simulation is displayed in Fig. 4.

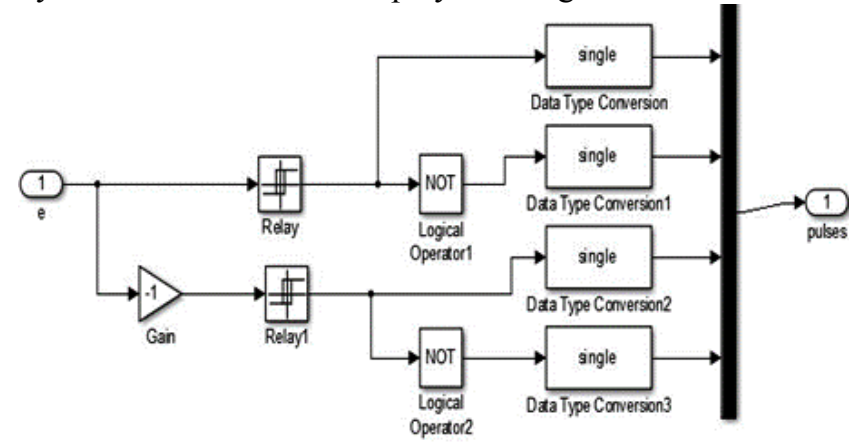

Fig. 4. Simulink Matlab for hysteresis controller

The output signal from the controller block in Fig 4 is used to trigger the switch on the inverter block. The inverter block is supplied from the supply voltage by a DC voltage source. The inverter's output voltage is connected in series with the resistor and inductor as the load. Current sensors are installed in series with a load to measure the amount of current. The measured current value is fed back and it is compared with the specified reference current signal. The single phase inverter simulation with the hysteresis current controller in Matlab is shown in Fig 5.

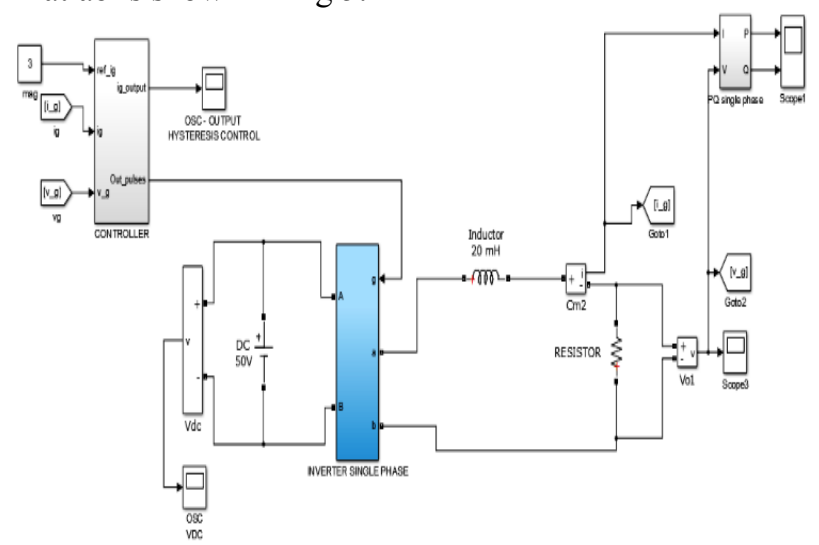

Fig. 5 Simulink Matlab for single phase inverter

The simulated parameters used in Fig 5 include 50 DC voltage as a supply of an inverter, an inductor mounted on an output inverter is $20 \mathrm{mH}$, the variable resistive load consist of $8 \Omega$ and $10 \Omega$, and the reference current is $1 \mathrm{~A}, 2 \mathrm{~A}$, and $3 \mathrm{~A}$. Output of Simulink for single phase inverter with hysteresis method is shown in Fig. 6 and Fig. 7

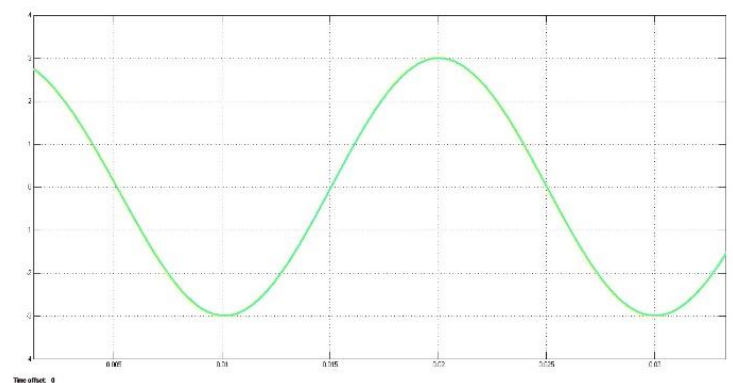

Fig. 6. Inverter current output during simulation

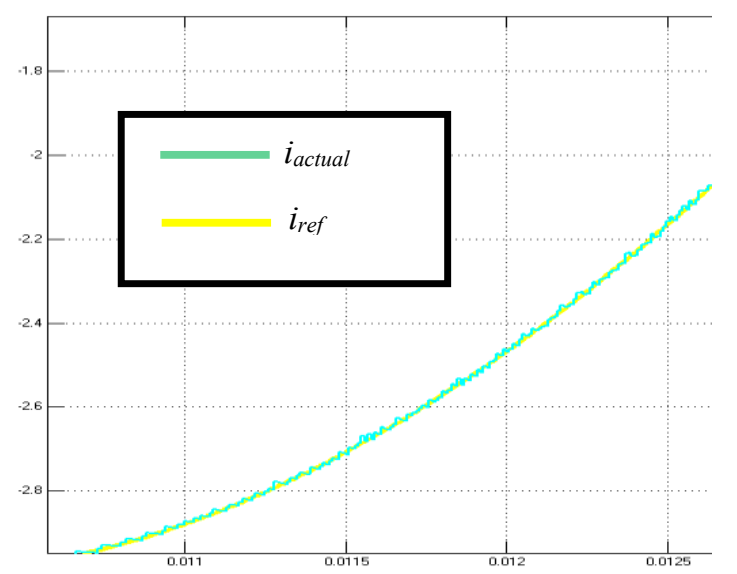

Fig. 7. Larger current profile for inverter output current at Fig. 6

\subsection{Experiment Result}

In this paper, the test aims to observe changes in the shape and magnitude of waves at the output of a singlephase inverter using the hysteresis method with 50 Volt DC input voltage and load at inverter output were $\mathrm{R}=8$ $\Omega$ and $\mathrm{R}=10 \Omega$. The reference current was set at $1 \mathrm{~A}$ to 3 A with upper and lower-band hysteresis was also set at 0.2 A. The setting of reference current was determined by the value of the potentiometer and the setting of bandwidth above was settled by the program in the DSPIC30F4011 microcontroller.

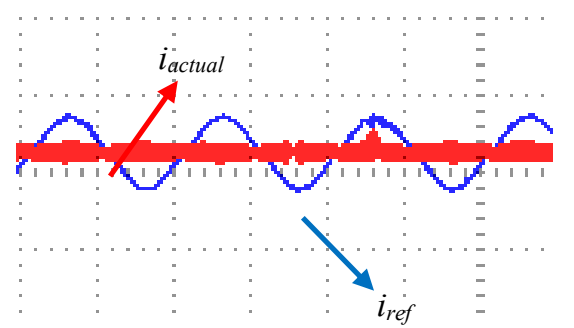

Fig. 8. Inverter current output with hysteresis control for $i_{\text {ref }}=1 \mathrm{~A}$ and $\mathrm{R}=8 \Omega$

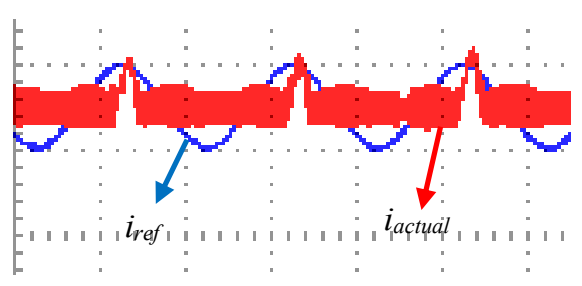

Fig. 9. Inverter current output with hysteresis control for $i_{\text {ref }}=1 \mathrm{~A}$ and $\mathrm{R}=10 \Omega$ 


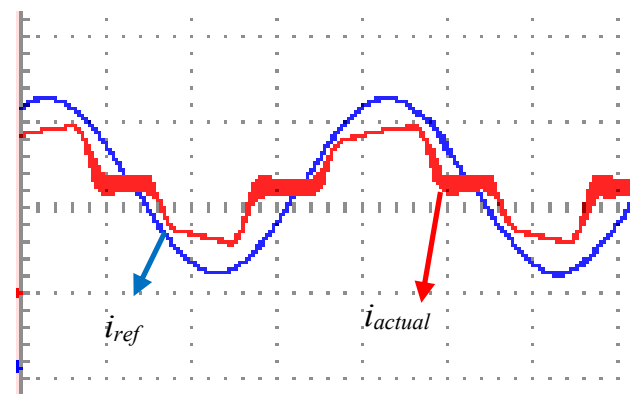

Fig. 10. Inverter current output with hysteresis control for $i_{\text {ref }}=2 \mathrm{~A}$ and $\mathrm{R}=8 \Omega$

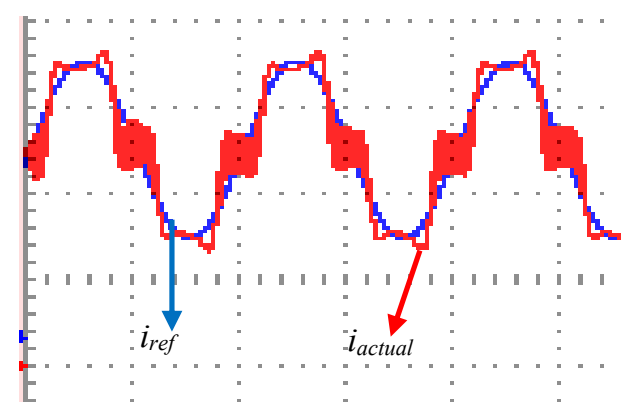

Fig. 11. Inverter current output with hysteresis control for $i_{r e f}=2 \mathrm{~A}$ and $\mathrm{R}=10 \Omega$

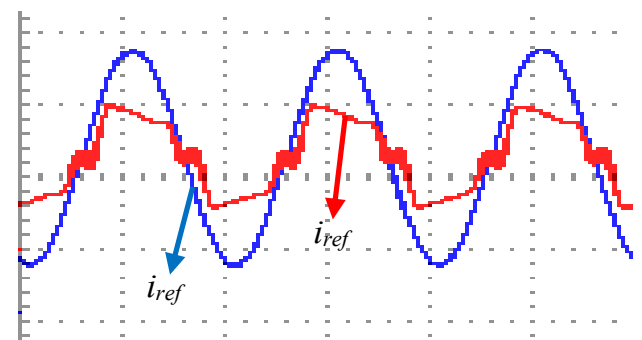

Fig. 12. Inverter current output with hysteresis control for $i_{\text {ref }}=3 \mathrm{~A}$ and $\mathrm{R}=8 \Omega$

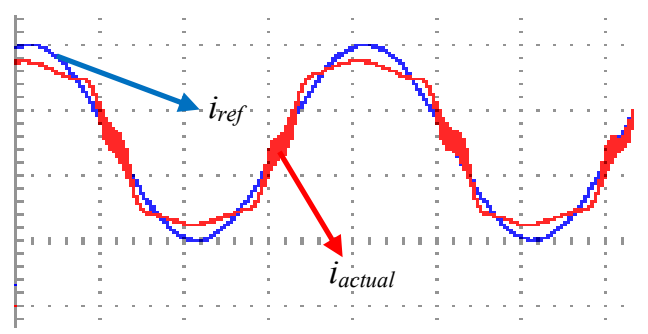

Fig. 13. Inverter current output with hysteresis control for $i_{\text {ref }}=3 \mathrm{~A}$ and $\mathrm{R}=10 \Omega$

Fig. 8 - 13 shows the inverter output current using the hysteresis method, where blue is the reference current $\left(i_{r e f}\right)$ and the red wave is the actual current $\left(i_{\text {actual }}\right)$. The picture shows the current control of a single phase inverter by using a hysteresis method to produce a good current signal form synchronized with the given reference current. The ripples are seen to be caused by switching effects that are controlled by hysteresis control where switching occurs based on a comparison of error flow. The actual current follows the reference current given from $1 \mathrm{~A}$ to $3 \mathrm{~A}$ with value resistor $\mathrm{R}=8 \Omega$ and $\mathrm{R}=$
$10 \Omega$ at controlled hysteresis limit of 0,2 A. Ripples at $\mathrm{R}$ $=8 \Omega$ are greater than $\mathrm{R}=10 \Omega$, so this phenomenon shows that if the given load is greater, the ripple is smaller. The value of the experimental results can be seen in Table 1.

Table 1. Results of single phase inverters with hysteresis method

\begin{tabular}{|c|c|c|}
\hline$i_{r e f}$ & Error $(\mathrm{R}=8 \Omega)$ & Error $(\mathrm{R}=10 \Omega)$ \\
\hline $1 \mathrm{~A}$ & 0,12 & $-0,08$ \\
\hline $2 \mathrm{~A}$ & $-0,72$ & $-0,28$ \\
\hline $3 \mathrm{~A}$ & 0,12 & 0 \\
\hline
\end{tabular}

\section{Conclusion}

The output current waveform on the inverter with the Hysteresis control can follow the reference current correctly, even though the load resistance value is changed. Hysteresis is caused by switching MOSFETs that are on and off when triggered by signal hysteresis control, where the control signal does not form a regular pattern because the control signal will move from 0 to 1 and from 1 to 0 directly based on the comparison of the error value and the given hysteresis limit. The current inverter output using hysteresis control can be synchronized with the reference current given, even though the load resistance value is changed. The experimental value shows that the difference between the reference current and the actual current has a very small error.

\section{Acknowledgement}

The authors would thanks for support from Strategic Research Grant 2019 based on Decree of Dean of Faculty of Engineering, Diponegoro University No. 167/UN.7.5.3/HK/2019 on April 22 ${ }^{\text {nd }}, 2019$.

\section{References}

1. N. Muluk, A. Warsito, I. Setiawan, Voltage Sag Mitigation Due To Short Circuit Current Using Dynamic Voltage Restorer Based On Hysteresis Controller, 108-112 (2017)

2. K. Selvakumar, R. Palanisamy, K. Vijayakumar, D. Karthikeyan, D. Selvabharathi, V. Kubendran, Hysteresis Control 3-Level SI-NPC Inverter with Wind Energy System, Int. J. Power Electron. Drive Syst. 8(4), 1764-1770 (2017)

3. S. Somkun, Electrical Power and Energy Systems Unbalanced Synchronous Reference Frame Control of Singe-Phase Stand-Alone Inverter, Electr. Power Energy Syst. 107, 332-343 (2019)

4. H.H. Moghaddam, M. Salimi, Applicability Improvement and Hysteresis Current Control Method Simplification in Shunt Active Filters, Iran. J. Electr. Electron. Eng. 11(3), 276-283 (2015)

5. S. Bhutada, S.R. Nigam, Single Phase PV Inverter Applying a Dual Boost Technology, Int. J. Appl. 
Power Eng. 5(2), 95-102 (2016)

6. A. Akhikpemelo, P. Matsunde, F.P. Ebenso, Simulation of Inverter Circuit Using Multism and Proteus, Cont. J. Eng. Sci. 11(2), 1-11 (2016)

7. A.A. Akbar, M. Facta, A. Nugroho, Designing a Full Bridge Inverter as a Speed Controller for Turning a Rotary Spark Gap Drive Motor, Transient 4(4), 895-901 (2015)

8. R. Dogga, M.K. Pathak, Recent Trends in Solar $P V$, Inverter Topologies Sol. Energy 183, 57-73 (2019)

9. T. Jamjaem, B. Burapattanasiri, High Precision HalfWave Rectifier Circuit In Dual Phase Output Mode, Int. J. Comput. Sci. Inf. Secur. IJCSIS 6(3), 149-152 (2009)

10. H. Mehar, The Case Study of Simulation of Power Converter Circuits Using Psim Software in Teaching, Am. J. Educ. Res. 1(4), 137-142 (2013)

11. C. Harkare, P. Kapoor, Study and Simulation of Current Controlled PWM Inverters and Their Applications, Int. J. Recent Innov. Trends Comput. Commun. 3(2), 138-142 (2015)

12. B.P. Reddy, K.S. Reddy, B.S.S. Reddy, Novel Single Phase Full Bridge Inverter Formed by Floating Capacitors, Int. J. Power Electron. Drive Syst. 7(1), 193-201 (2016) 